\title{
Effectiveness of Personalized Virtual Reality with Game Components Behavioral Intervention on Smoking Cessation
}

\author{
Shuyuan Liu \\ Department of Psychology, York University, Toronto, ON, Canada, M3J 1P3 \\ *Corresponding author. Email: dario96@my.yorku.ca
}

\begin{abstract}
Smoking is gradually becoming a concern for most people due to its harm to the lungs, heart, and immune system. Psychological approaches such as cognitive behavior therapy, cue exposed therapy, behavioral change techniques, and motivational interview, are mainstream to treat smoking addiction. However, relapse after quitting smoking is still a significant issue for conventional treatment. Virtual reality (VR) technology is gradually becoming a tool to facilitate behavior therapy toward smoking cessation, but it does not significantly increase the treatment's effectiveness. This paper analyses the potential effectiveness of VR-gamification in quitting smoking, and a literature review is used to analyze this topic. In this paper, the author proves that adding game elements to the treatment could promote the user's self-efficacy and motivation to quit smoking. With the flow features applied in the game, the user could have a sense of their ability compared to game difficulty. This would make the user feel that they are having fun and that they are engaged and challenged. It would therefore inhibit the user's dropout rate. Additionally, gamification should include personalization, social support, a meaningful frame, a user-centered design, and emotion and enjoyment to facilitate further intrinsic motivation to quit.
\end{abstract}

Keywords: Smoking Cessation, Gamification, VR, Virtual Reality, Smoking, Digital Therapy, Motivation, Self-efficacy

\section{INTRODUCTION}

One of the major health issues concerning health scientists is the harm of smoking addiction, with various health problems such as lung disease, heart diseases, cancer, diabetes, chronic obstructive pulmonary disease, eye disease, immunological problems, and erectile dysfunction in males. Currently, over 16 million Americans are suffering from smoking-related diseases [1]. Long-term smoking could even cause preventable death. Data from Verywelmind shows that 7.7 million deaths worldwide result from smoking. CDC explains that smoking cigarettes may reduce smoker's longevity by 10 years [1]. FDA reports that in 2015, around 70 percent of smokers in America wanted to quit, and up to 2018, nearly 55 percent of smokers had tried to quit, but less than 10 percent had quit completely [2].

Psychological interventions, such as cognitive behavioral therapy (CBT), cue exposed therapy (CET), behavioral change techniques (BCT), and motivational interview (MI), have been viewed as essential ways to treat smoking addiction, but these have a high relapse rate caused by withdrawal, craving, low adherence, high nicotine dependence, and a lack of smoking cessation aids. VR technology has proven to be a well-established supplemental tool to facilitate the assessment and treatment of smoking addiction as it simulates drugrelated cues and environments to induce craving. VR CET intervention has been investigated most extensively, and it has proven effective in recreating craving induction in a more life-like and compelling way than conventional interventions [3]. However, the effectiveness of other alternative interventions such as CBT and MI have remained controversial. This paper will discuss this topic through gamification with behavioral change, psychological outcome, and intrinsic motivation. This research suggests a novel development for behavioral therapists and game developers to design and apply a gamified strategy that will enhance the current digitalized addiction treatment for smoking and other kinds of dependence. 


\section{GAMIFICATION EMPOWERMENT}

Most recent findings show the potential effectiveness of gamified intervention in behavioral therapy combined with psychological coaching. This potential effectiveness could further be enhanced by adding game components to the treatment. A well-designed game could elicit participants' engagement in therapy by raising their intrinsic motivation, resulting in a higher treatment adherence rate and lower dropout rate than traditional therapy [4]. Therefore, the effectiveness of gamified intervention and therapy is an essential advantage over the higher dropout rate of conventional smoking addiction therapy.

The gamification-based intervention takes advantage of the potential motivational interaction of a game, encouraging the user to complete the task more efficiently and enjoyably, which greatly empowers the user's adherence and engagement. As shown in Fig 1, a systematic meta-analysis shows that applying game components could generate motivational affordance, resulting in a psychological outcome and further facilitating behavioral change [5].

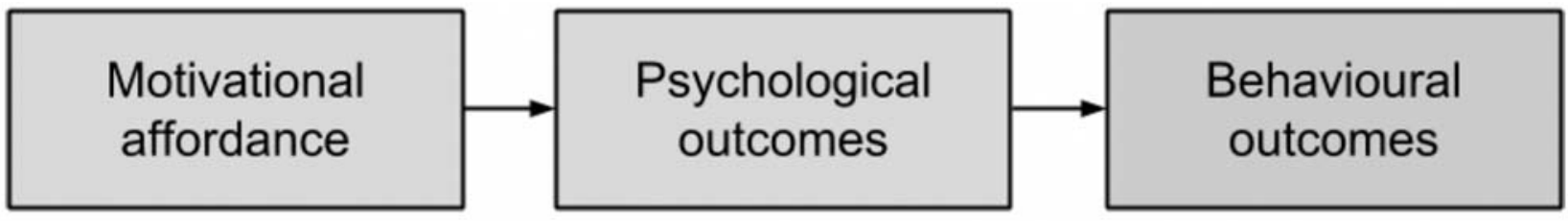

Figure 1 How motivational affordances lead to behavioral outcomes [5].

\subsection{Gamification and Behavioral Change}

Cugelman states that gamification has proven components in common with behavioral change techniques, and they can be implemented in current digital health interventions by adding different reinforcements to make the interventions more socialized, interactive, innovative, and engaging [6]. He argues that his identification of the seven core components of gamification architecture (Fig. 2.) has a strong link to behavioral change strategies in a fun and playful way, but they are ignored in most of the literature [6].

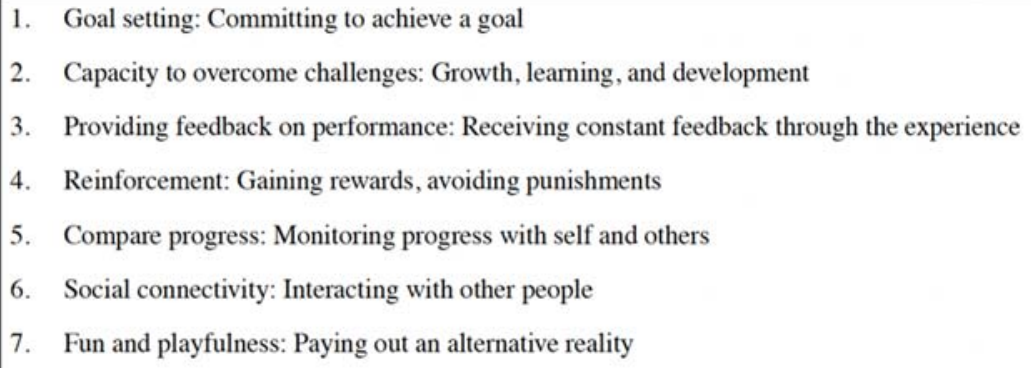

Figure 2 The persuasive architecture of gamification and its 7 persuasive strategies.

\subsection{Gamification and the Psychological Outcome}

Unlike behavior change intervention, one significant difference of the game principle is to use flow to form behavior, where people absorb and become engaged in a task that allows the user's capabilities to match the level of challenge in the game. As shown in Fig. 3, people do not have to feel bored if their capability is higher than the game's level of difficulty, and they do not have to feel anxious if the game's level of difficulty is beyond their control. This is important because when the challenge level matches the user's skill level, the user will feel a sense of absorption in what they are doing and therefore ensure the user's consistent engagement. This is always the goal of the game.

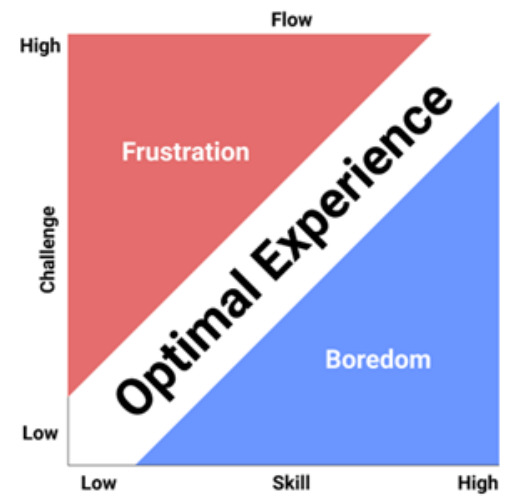

Figure 3 Model of the flow experience [7].

\subsection{Gamification and Intrinsic Motivation}

According to Fig. 4, research shows that gamification has promising effects in turning regularly assigned exercises into fun interactive games. In their paper, 
Abdulrahman et al. suggest that gamified intervention could elicit the user's intrinsic motivation to a greater degree than non-gamified intervention. A systematic literature review by Joy et al. also indicates that seven out

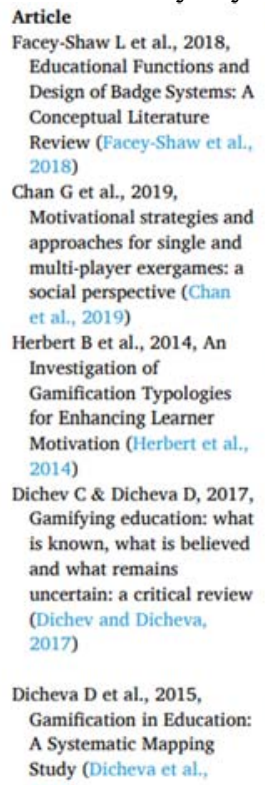

of 10 support the idea that gamification could raise the user's intrinsic motivation. The remaining three are not relevant to the research topic [8].

\begin{tabular}{|c|c|c|}
\hline $\begin{array}{l}\text { Mosalanejad L et al., 2018, } \\
\text { Educational Game: A Fun } \\
\text { and team based learning in } \\
\text { psychiatric course and its } \\
\text { effects on Learning } \\
\text { Indicators (Mosalanejad } \\
\text { et al., 2018) }\end{array}$ & $\begin{array}{l}\text { Gamification } \\
\text { improves intrinsic } \\
\text { motivation }\end{array}$ & $\begin{array}{l}\text { Gamification improved } \\
\text { learning through increasing } \\
\text { engagement. }\end{array}$ \\
\hline $\begin{array}{l}\text { Piras L et al., 2019, Design } \\
\text { Thinking and Acceptance } \\
\text { Requirements for } \\
\text { Designing Gamified } \\
\text { Software (Piras et al., } \\
\text { 2019) }\end{array}$ & $\begin{array}{l}\text { Gamification } \\
\text { improves intrinsic } \\
\text { motivation }\end{array}$ & $\begin{array}{l}\text { Design thinking improves } \\
\text { effects of gamification }\end{array}$ \\
\hline $\begin{array}{l}\text { Saputro RE et al., 2019, A } \\
\text { gamification framework to } \\
\text { enhance students' intrinsic } \\
\text { motivation on MOOC ( } \\
\text { Saputro et al., 2019) }\end{array}$ & $\begin{array}{l}\text { Gamification } \\
\text { improves intrinsic } \\
\text { motivation }\end{array}$ & $\begin{array}{l}\text { New gamification platform } \\
\text { increases student intrinsic } \\
\text { motivation in online course } \\
\text { format }\end{array}$ \\
\hline $\begin{array}{l}\text { Zhang R, 2020, Game-based } \\
\text { self-regulated language } \\
\text { learning: Theoretical } \\
\text { analysis and bibliometrics ( } \\
\text { Zhang et al., 2020) }\end{array}$ & $\begin{array}{l}\text { Not relevant to } \\
\text { research question }\end{array}$ & $\begin{array}{l}\text { Game Based Self-Regulated } \\
\text { Language Learning } \\
\text { (GBSRLL) has been receiving } \\
\text { more attention, specifically } \\
\text { in the fields of learning } \\
\text { strategies and the effect of } \\
\text { GBSRLL on learner states } \\
\text { and its features. }\end{array}$ \\
\hline $\begin{array}{l}\text { Connolly TM et al., 2012, A } \\
\text { systematic literature } \\
\text { review of empirical } \\
\text { evidence on computer } \\
\text { games and serious games ( } \\
\text { Connolly et al., 2012) }\end{array}$ & $\begin{array}{l}\text { Not relevant to } \\
\text { research question }\end{array}$ & $\begin{array}{l}\text { Serious game studies used } \\
\text { quasi-experiments more, } \\
\text { studies of entertainment } \\
\text { games used quasi- } \\
\text { experiments and surveys. } \\
\text { RCTs and qualitative designs } \\
\text { were uncommon. }\end{array}$ \\
\hline
\end{tabular}

Figure 4 Findings and outcomes of articles that were rated $5 / 5(n=10)$ [8].

Compared with the non-gamified group, the gamified group has a higher engagement driven by the game's motivational affordances, such as level progress, rewards, or virtual coins [5]. They suggest that the challenges divided into small pieces could enhance individuals' control beliefs and, therefore, have stronger perceived behavioral control (PBC) and self-efficacy.

The self-determination theory demonstrates that gamification could instill a sense of intrinsically motivating competence in the user by showing the informational feedback of the game elements such as the achievements and rewards of the tasks [9]. The reward in the game serves as a conditional stimulus that could positively reinforce the desired behavior [5]. In contrast, the user could be frustrated by seeing the degree level degraded because of aversive behavior or smoking, which is known as aversive loss [5].

The goal-setting theory explains the individual's intrinsic motivation from another angle, stating that gamification components such as degrees or levels of progress provide the individual with smaller but more immediate goals that the user can engage in to achieve and therefore raise the individual's confidence about their capabilities in completing their tasks.

An observational study from Nikita et al. explores the effect of gamification on self-efficacy and motivation to quit smoking by comparing the individual engaging in two different gamified smoking cessation apps. The smoking self-efficacy questionnaire is used to measure the participant's confidence in their capability to refrain from smoking. A total score ranging from 12 to 60 is used for each participant, with the higher score meaning higher self-efficacy. Additionally, the motivation to quit is measured by asking two items that are often used in most smoking cessation: "How important is it to you to give up smoking altogether with this attempt?" and "How determined are you to give up smoking with this attempt?" The participants were provided specific options to answer these two questions, and the total score range from 2 to 8 is used to measure the motivation. A higher score means a higher motivation to quit.

As shown in Fig. 5, by conducting four weeks of observational study with 116 participants who completed the study, Nikita et al. found that the mean of participants' motivation to quit increased to $4.4 \%$ after two weeks and $6.4 \%$ after four weeks of using the app, and the median of motivation to quit was at baseline after six weeks of using the app and seven out of four weeks of using the app. Additionally, the mean of self-efficacy increased by $10.67 \%$ after two weeks of using the app and $13.62 \%$ after four weeks of using the app. The median was also an uptrend pattern which was seven at baseline. It increased to 42.5 after two weeks of using the app and 44 after four weeks of using the app. They conducted a t test and found that the amount of difference in the mean of baseline and mid-study as well as baseline and end-study in both self-efficacy and motivations to quit and were statistically significant. 


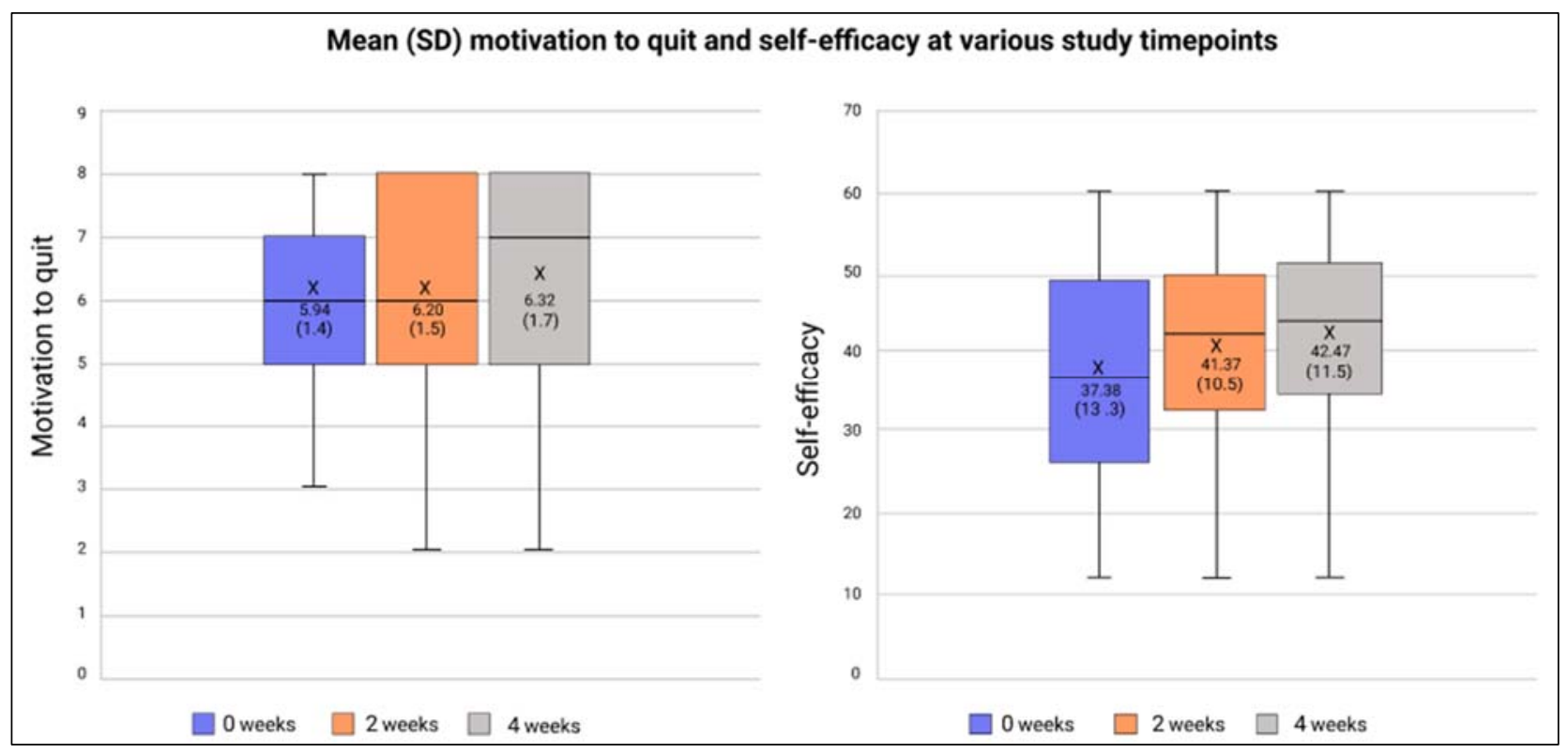

Figure 5 Self-efficacy and motivation to quit at baseline, midstudy, and end-study (n=116) [9].

\section{ESSENTIAL COMPONENTS FOR GAME DESIGN}

\subsection{Social Support}

The network also plays a crucial role in impacting $\mathrm{PBC}$. The individual has stronger $\mathrm{PBC}$ and is more motivated to quit when he/she receives social support, which is essential in his/her psychological and physical well-being and helps prevent relapse after quitting smoking [10].

\subsection{Personalization}

Although adding gamification to quit smoking may promote the user's motivation, one-size-fits-all (OSFA) gamification undermines the potential to elicit a user's intrinsic motivation fully because everyone has different expectations in playing games and engaging in therapy. However, Luiz et al. suggest that multidimensional personalized gamification has a positive effect on promoting intrinsic motivation, explaining that personalized gamification designs could make the game components more suitable to a user's preference, and this possibly explains why the individual perceives it as raised intrinsic motivation and need-supporting [11]. With the right psychological needs support, the user would have a higher autonomous motivation, which motivates the user to engage in a behavior consistent with the intrinsic goal [12]. This, however, cannot be generated in the OSFA [11].

\subsection{Meaningful Frame}

How meaning is framed is another essential component of gamification engagement. The user would feel more value in an activity as they are engaging in a meaningful activity that supports his/her intrinsic interest, goal, or purpose because the user views such meaningful activity as intrinsic reward itself more likely to contribute his/her effort to it to create significance that may last for long [13].

\subsection{User-Centered Design}

User-centered design should also be considered while designing gamification for quitting smoking. It is a user research process to understand the user's needs and goals in multidimensions, which needs to be taken into consideration in every step of gamification design. A well-established user-centered design may further induce an individual's intrinsic motivation to quit smoking [14].

\subsection{Emotion and Enjoyment}

The hedonic quality of the gamification is gradually becoming a crucial component of enhancing the user's experience of quitting smoking. Behavior formation consists of the consequence of the behavior that is performed, so if the user feels a joy in use as he or she is using the product to quit smoking, he or she will be more likely to use the product again in the future. Torben et al. argue that the interface of gamification should be considered more for creating positive emotions in the design process to maximize usability, suggesting that positive experiences such as pleasure, enjoyment, and fun, should be created to relate the user's satisfaction as he or she is engaging in smoking cessation through such an interface [14].

\section{DISCUSSION}

Through the systematic literature review, the author found that gamification is associated with increased intrinsic motivation and self-efficacy, which is generated 
by a participant's frequent engagement in gamification features.

Gamification has been proven a common element shared with health behavioral change techniques. Behavior may be changed through digital interventions via gamification principles in consideration of flow, reward, socialization, and how to use innovative techniques to make digital interventions more engaging and fun. This significantly increases participants' selfefficacy, considerably elevating the participants' competence in the game and confidence in their ability to quit smoking. With a game design that is based on personalization, user-centered design, emotion and enjoyment, meaningful frame, and flow, the individual may be more likely to engage in gamification, and with consistent engagement in gamification, the user's intrinsic motivation may be significantly increased, indicating that participants may experience higher selfdetermination and significance in successfully quitting.

\section{CONCLUSION}

Gamification shares the same behavioral change techniques as the psychological principles of behavioral change or modification. This validates the effectiveness of engaging gamification to reach the goal of behavioral change. However, one significant difference is that flow is widely used in the game to form the behavior, and the application of flow greatly ensures that the user feels that he or she is experiencing fun, is engaged, and is challenged while playing the game.

In addition, the effectiveness of gamification on quitting smoking is associated with intrinsic motivation and self-efficacy. The more consistent the engagement with gamification for smoking cessation, the higher the self-efficacy and motivation to quit. Essential components such as personalization, social support, usercentered design, meaningful frames, and emotions and enjoyment determine the user's engagement and consistency in the use of gamification.

However, research on the application of VR gamification to assist in smoking cessation is limited. Thus, the effectiveness of VR gamification is still unknown. Based on the validated effectiveness of gamification on smoking cessation and the current application of VR in treating smoking addiction, more research and experiments in VR gamification for quitting smoking are needed to examine its potential effectiveness.

\section{REFERENCES}

[1] Centers for Disease Control and Prevention, Health effects, Centers for Disease Control and Prevention. (2020). Retrieved November 21, 2021, from https://www.cdc.gov/tobacco/basic_information/he alth_effects/index.htm.

[2] FDA. What it's like to quit smoking, U.S. Food and Drug Administration. (2021). Retrieved November 21, 2021, from https://www.fda.gov/tobaccoproducts/health-effects-tobacco-use/what-its-quitsmoking.

[3] Livingstone-Banks, J., Norris, E., Hartmann-Boyce, J., West, R., Jarvis, M., \& Hajek, P., Relapse prevention interventions for smoking cessation, The Cochrane Database of Systematic Reviews. (2019).

Retrieved November 21, 2021, from https://www.ncbi.nlm.nih.gov/pmc/articles/PMC63 72978/.

[4] Goldenhersch, E., Thrul, J., Ungaretti, J., Rosencovich, N., Waitman, C., \& Ceberio, M. R., Virtual reality smartphone-based intervention for Smoking Cessation: Pilot randomized controlled trial on initial clinical efficacy and adherence, Journal of Medical Internet Research. (2020). Retrieved November 21, 2021, from https://www.ncbi.nlm.nih.gov/pmc/articles/PMC74 $24475 /$.

[5] El-Hilly, A. A., Iqbal, S. S., Ahmed, M., Sherwani, Y., Muntasir, M., Siddiqui, S., Al-Fagih, Z., Usmani, O., \& Eisingerich, A. B., Game on? Smoking cessation through the gamification of mHealth: A longitudinal qualitative study JMIR Serious Games, 4(2). (2016). https://doi.org/10.2196/games.5678.

[6] Cugelman, B., Gamification: What it is and why it matters to Digital Health Behavior Change Developers, JMIR Serious Games, 1(1) (2013). https://doi.org/10.2196/games.3139.

[7] Marczewski, A., Optimal experience in gamification, Gamified UK - \#Gamification Expert. Retrieved November 21, 2021, from https://www.gamified.uk/2017/09/25/optimalexperience-gamification/.

[8] Xu, J., Lio, A., Dhaliwal, H., Andrei, S., Balakrishnan, S., Nagani, U., \& Samadder, S., Psychological interventions of virtual gamification as a motivational basis: A mixed-method systematic review. (2021). https://doi.org/10.21203/rs.3.rs$607400 / \mathrm{v} 1$.

[9] Rajani, N. B., Mastellos, N., \& Filippidis, F. T., Impact of gamification on the self-efficacy and motivation of smokers to quit: Observational study of two gamified smoking cessation mobile apps. JMIR Serious Games, 9(2). (2021). https://doi.org/10.2196/27290. 
[10] Soulakova, J. N., Tang, C.-Y., Leonardo, S. A., \& Taliaferro, L. A., Motivational benefits of social support and behavioural interventions for smoking cessation, Journal of Smoking Cessation. (2018). Retrieved November 21, 2021, from https://www.ncbi.nlm.nih.gov/pmc/articles/PMC64 59678/.

[11] Rodrigues, L., Palomino, P. T., Toda, A. M., Klock, A. C., Oliveira, W., Avila-Santos, A. P., Gasparini, I., \& Isotani, S., Personalization improves gamification, Proceedings of the ACM on HumanComputer Interaction, 5(CHI PLAY), 1-25 (2021). https://doi.org/10.1145/3474714.

[12] Hagger, M. S., Hardcastle, S. J., Chater, A., Mallett, C., Pal, S., \& Chatzisarantis, N. L. D.,. Autonomous and controlled motivational regulations for multiple health-related behaviors: Between- and withinparticipants analyses, Health Psychology and Behavioral Medicine. (2014). Retrieved November 21, 2021, from https://www.ncbi.nlm.nih.gov/pmc/articles/PMC43 46087/.

[13] Mekler, E. D., Brühlmann, F., Opwis, K., \& Tuch, A. N. Disassembling gamification. CHI '13 Extended Abstracts on Human Factors in Computing Systems on - CHI EA '13. (2013). https://doi.org/10.1145/2468356.2468559.

[14] Wiedenhoefer, T., Yetim, F., \& Rohde, M., UserCentered Design Goals for Motivating Participation in Socially Embedded Software Tools. (2010). https://www.wineme.unisiegen.de/paper/2010/coop2010_workshop_motiva ting-participation_12042010_submitted.pdf.

Retrieved November 21, 2021, from https://www.iisi.de/wpcontent/uploads/2018/07/irsi_vol7_iss1_wiedenhoe fer_yetim_rohde_usercentered_design_goals_for_motivating_participati on.pdf. 